\title{
Author Correction: Biodiversity targets will not be met without debt and tax justice
}

Jessica Dempsey (D), Audrey Irvine-Broque, Patrick Bigger (D), Jens Christiansen, Bhumika Muchhala, Sara Nelson (i), Fernanda Rojas-Marchini (D), Elizabeth Shapiro-Garza B), Andrew Schuldt (1) and Adriana DiSilvestro

Correction to: Nature Ecology \& Evolution https://doi.org/10.1038/s41559-021-01619-5, published online 20 December 2021.

In the version of this article initially published, the second sentence of the "Multilateral tax reform" section referring to financial losses to governments was unclear. It has been clarified to state that it is tax havens in general, not only tax avoidance by Fortune 500 companies, that cost governments USD 500-600 billion a year in lost taxation. It has also been corrected to refer to an estimated loss of USD 200 billion to non-OECD economies rather than to low-income countries. The changes have been made to the HTML and PDF versions of the article.

Published online: 18 February 2022

https://doi.org/10.1038/s41559-022-01704-3

๑) Springer Nature Limited 2022 